\title{
La desnaturalización de las proteínas de la leche y su influencia en el rendimiento del queso fresco
}

\section{(Denaturation of milk proteins and their influence on the yield of fresh cheese)}

\author{
Ana Mejía-López ${ }^{1}$, Sonia Rodas ${ }^{1}$, Darío Baño ${ }^{1}$
}

\begin{abstract}
Resumen:
Para determinar la desnaturalización que sufren las proteínas de la leche por los efectos del tratamiento térmico en la pasteurización y establecer su influencia en el rendimiento del queso fresco fabricado, se hicieron 20 producciones a escala de laboratorio y 40 producciones en planta. Se empleó leche cruda y tratada a $65^{\circ} \mathrm{C}$ por 30 minutos, $72{ }^{\circ} \mathrm{C}$ por 15 segundos y a ebullición por 2 segundos, y se cuantificó la proteína en la leche para calcular el porcentaje de desnaturalización. En el queso se determinó el contenido de humedad y se cuantificó la cantidad de queso obtenido. Los datos fueron procesados mediante análisis de medias de Tukey. Los resultados a nivel de laboratorio reflejaron que el incremento de temperatura provocó mayor desnaturalización de las proteínas, un mayor rendimiento y un aumento de humedad en el queso en relación al obtenido con la leche cruda. Sin embargo, estadísticamente los resultados demostraron que el tratamiento térmico sí influye en la desnaturalización de las proteínas pero no en el rendimiento del queso. Los resultados obtenidos en la investigación en fábrica revelaron que a temperatura de 65 y $72{ }^{\circ} \mathrm{C}$ el rendimiento disminuye con relación a la producción con leche cruda, pero estadísticamente no presenta diferencias significativas en el rendimiento para leche pasteurizada a $65^{\circ} \mathrm{C}$ por 30 minutos y la leche cruda, concluyendo que la pasteurización a diferentes temperaturas desnaturalizan la proteína pero no influye en el rendimiento del queso fresco elaborado.
\end{abstract}

Palabras clave: queso fresco; desnaturalización; tratamiento térmico; leche

\begin{abstract}
:
To determine the denaturation of milk proteins by the effects of heat treatment on pasteurization and to establish their influence on the yield of the fresh cheese manufactured, 20 laboratoryscale controlled trials and 40 plant productions were made. Crude and treated milk was used at $65^{\circ} \mathrm{C}$ for 30 minutes, $72{ }^{\circ} \mathrm{C}$ for 15 seconds and boiled for 2 seconds, and the protein was quantified in milk to calculate percent denaturation. In the cheese the moisture content was determined and the amount of cheese obtained was quantified. The data were processed by Tukey's mean analysis ( $p>0.05)$. The results at the laboratory level showed that the increase in temperature caused higher denaturation of the proteins, a higher yield and an increase in moisture in the cheese compared to that obtained with raw milk. However, statistically the results showed that the heat treatment does influence the denaturation of the proteins but not the performance of the cheese. The results obtained in the factory investigation revealed that at 65 and $72{ }^{\circ} \mathrm{C}$ the yield decreases relative to the production with raw milk, but statistically does not present significant differences in the yield, concluding that the pasteurization at different temperatures denature the protein But does not influence the performance of fresh processed cheese.
\end{abstract}

Keywords: fresh cheese; performance; denaturation; heat treatment; milk

\footnotetext{
${ }^{1}$ Universidad Nacional de Chimborazo, Riobamba - Ecuador ( \{anamejia, srodas, dbano\} @unach.edu.ec )
} 


\section{Introducción}

Las microempresas del sector lácteo en Ecuador fabrican queso principalmente del tipo fresco no madurado, es decir de aquel que se debe consumir inmediatamente después de la fabricación, utilizando como materia prima indistintamente la leche cruda o la leche pasteurizada. Aunque es conocido que la pasteurización ayuda a brindar leche y quesos inocuos, todavía la mayoría de los productores de las microempresas creen que la pasteurización daña a la leche y produce menos quesos que la leche sin pasteurizar. Esto se debe al desconocimiento o la poca información sobre el efecto del tratamiento térmico en la elaboración del queso fresco y particularmente en las proteínas, las cuales son las que intervienen mayoritariamente en la obtención del mismo.

Estudios realizados en diferentes trabajos demuestran que los tratamientos térmicos provocan la desnaturalización de las proteínas, es decir producen un cambio en la estructura física de las proteínas, pero en general no afectan a la composición de aminoácidos y por lo tanto a las propiedades nutricionales de la leche. Las $\beta$-lactoglobulinas son las más afectadas en estos tratamientos (Rynne et al., 2004) proporcionando el "gusto ácido" de la leche, mientras que las micelas de caseína son notablemente estables e incluso a temperaturas de hasta $140{ }^{\circ} \mathrm{C}$ (Tornadijo et al., 1998). Sin embargo, cuando se calienta por encima de los $100^{\circ} \mathrm{C}$ puede existir una disminución del $\mathrm{pH}$, que es causada por la formación de ácidos orgánicos de la degradación de la lactosa y la precipitación de fosfato de calcio (Martínez-Castro et al., 1986).

La desnaturalización ofrece importantes ventajas tales como el aumento del rendimiento y del valor nutritivo del queso (Kethireddipalli et al., 2010) y la destrucción de bacterias tanto benéficas como perjudiciales. Rodríguez (2002) plantea que la leche puede tener alteraciones físicas y pérdidas importantes del valor nutritivo cuando sufre tratamiento térmico excesivo, como por ejemplo la pérdida de lactosa a través de la reacción de Maillard, que produce sabores y colores indeseables. La disminución en el contenido disponible del aminoácido lisina es entre 1-2\% por efecto de la pasteurización y entre $2-4 \%$ por esterilización a altas temperaturas. Sin embargo, tratamientos más severos como la concentración por evaporación a alta temperatura o la esterilización en tarro pueden causar pérdidas de más de 20\% (Fennema,1985). Otros cambios significativos en las proteínas que se producen en el calentamiento de la leche por encima de los $60 \stackrel{\circ}{\circ}$ incluyen la desnaturalización de las proteínas del suero, las interacciones entre las proteínas de suero desnaturalizadas y las micelas de caseína y la conversión del calcio, magnesio y fosfato solubles en estado coloidal (Singh y Waungana, 2001).

La pasteurización de la leche en las microempresas se realiza en forma discontinua aplicando fuego directo, o con vapor, a diferentes temperaturas. Las temperaturas más utilizadas son entre 63 a $65{ }^{\circ} \mathrm{C}$ por un tiempo de 30 minutos y de $72^{\circ} \mathrm{C}$ por 15 a 20 segundos. Entonces es de importancia conocer cuál es el grado de la desnaturalización de las proteínas y cómo esto afecta en el rendimiento del proceso de los quesos elaborados en condiciones controladas en el 
laboratorio y en condiciones reales en fábrica. El objetivo de este estudio es evaluar los cambios que se producen en la leche al ser sometida a diferentes tiempos y temperaturas y su influencia en la calidad y rendimiento del queso fresco. Para esto se cuantificó el porcentaje de proteína en la leche cruda y tratada a tres niveles de temperatura y tiempos de sostenimiento, se calculó el porcentaje de desnaturalización de la proteína en la leche y se determinó el porcentaje de humedad y el rendimiento de los quesos.

\section{Metodología}

Este estudio fue desarrollado en el laboratorio de Control de Calidad de Alimentos de la Universidad Nacional de Chimborazo y en la planta de producción de la microempresa "Lácteos San Salvador" del cantón Riobamba, provincia de Chimborazo, ubicado en la sierra central del Ecuador.

\subsection{Diseño experimental.}

Se utilizó un diseño experimental completamente aleatorizado a dos niveles: un nivel controlado en laboratorio y un nivel en condiciones reales de fábrica.

A nivel de laboratorio, se trataron 20 unidades experimentales desglosadas en 4 tratamientos con 5 réplicas. Los tratamientos consistieron en (1) leche cruda o sin pasteurización, (2) leche pasteurizadas a $65^{\circ} \mathrm{C}$ por 30 minutos, (3) leche pasteurizada a $72^{\circ} \mathrm{C}$ por 15 segundos, y (4) leche pasteurizada a punto de ebullición por 2 segundos. Para cada repetición se utilizaron 10,5 litros de leche repartida de la siguiente manera: 0,5 litros para determinar la calidad de la materia prima, y para cada tratamiento 2,5 litros de los cuales 0,5 litros fueron utilizados para determinar por duplicado el porcentaje de proteína que permitió calcular el porcentaje de desnaturalización, y 2 litros para elaborar el queso en el cual se determinó el peso y el porcentaje de humedad.

A nivel de fábrica se realizaron 40 unidades experimentales (4 tratamientos con 10 repeticiones). Para cada unidad experimental se utilizaron 500 litros de leche y se fabricaron queso en moldes de 700 gramos. Para determinar la influencia en el rendimiento se contó el número de quesos fabricados y se calculó el rendimiento en kilogramos de queso por 100 kilogramos de leche.

\subsection{Procedimientos}

\subsubsection{Análisis físico químicos}

Para el control de calidad de la leche se utilizó el analizador de Leche Ultrasónico, marca Milkotester, con el cual se cuantificaron los parámetros de densidad, grasa, proteínas y punto crioscópico. Para la determinación de acidez, pH, prueba de alcohol y prueba de azul de metileno, se siguieron los métodos de ensayo NTE INEN 13, 973, 018 y 1500 respectivamente. 


\subsubsection{Determinación del porcentaje de desnaturalización}

El procedimiento aplicado fue el descrito por Manji y Kakuda (1987) que consiste en calcular el porcentaje de desnaturalización comparando el porcentaje de nitrógeno de la leche tratada térmicamente con el porcentaje de nitrógeno de la leche cruda, mediante la ecuación

$$
\% \text { Desnaturalización }=\frac{\text { WPNraw }- \text { WPNheated }}{\text { WPNraw }} \times 100 \text {, }
$$

dónde WPNraw es el porcentaje de nitrógeno de la leche cruda y WPNheated el porcentaje de nitrógeno de la leche pasteurizada.

En nuestro caso se tomaron los 0,5 litros de leche y se filtraron para garantizar que no existan impurezas o cuerpos extraños. Luego se pasteurizaron en baño maría a las diferentes temperaturas y tiempos indicados anteriormente con agitación manual constante. Finalmente las muestras se enfriaron rápidamente hasta una temperatura de $20{ }^{\circ} \mathrm{C}$ y se filtraron al vacío. El porcentaje de nitrógeno se determinó por el método de Kjeldahl (Método de digestión en parrilla usando cobre como catalizador y una unidad de destilación con vapor marca VELP). El porcentaje de proteína se calculó utilizando el factor 6,38 correspondientes a lácteos.

\subsubsection{Proceso de elaboración del queso fresco}

Para la elaboración del queso fresco en el laboratorio se siguió el mismo procedimiento utilizado por la microempresa "San Salvador" que consistió en los siguientes pasos:

1) Subir la temperatura de la leche a las tres temperaturas bajo estudio, $65^{\circ} \mathrm{C}, 72{ }^{\circ} \mathrm{C}$ y a punto de ebullición, en el menor tiempo posible. Dejar transcurrir 30 minutos, 15 segundos y 2 segundo respectivamente y enfriar rápidamente hasta alcanzar $40^{\circ} \mathrm{C}$.

2) Para la producción de queso con leche cruda subir la temperatura hasta $40{ }^{\circ} \mathrm{C}$.

3) A todos los tratamientos se adicionó $0,02 \% \mathrm{~m} / \mathrm{m}$ de cloruro de calcio (a nivel de fábrica la cuajada del tratamiento a punto de ebullición fue muy blanda y difícil de manejar por lo cual se adicionó el doble de cloruro de calcio).

4) Se enfrió a $38^{\circ} \mathrm{C}$ para adicionar la cantidad de cuajo recomendado por el fabricante y se dejó reposar por 30 minutos para que se forme la cuajada.

5) Transcurrido el tiempo se realizó mediante batido lento el corte de la cuajada, se procedió al desuerado, moldeado, enmallado y prensado por 2 horas.

6) Se sumergieon los quesos en sal muera por 2 horas y se orearon por 5 minutos.

\subsection{Análisis estadístico}

Los resultados de cada uno de los parámetros determinados fueron procesados mediante un análisis de varianza ANOVA de un factor y los promedios se compararon por el test de Tukey con un nivel de significancia de 0,05 con el uso del programa estadístico SPSS. 


\section{Resultados y discusión}

\subsection{Calidad de la leche}

La Tabla 1 muestra el análisis fisicoquímico de la leche entera. Los niveles indicados se encuentran dentro de los requisitos que establece la Norma INEN 9:2012 para leche cruda y corresponden a leche de buena calidad.

Tabla 1. Promedios del análisis fisicoquímico de la leche cruda

\begin{tabular}{|l|c|c|c|}
\hline \multirow{2}{*}{ PARÁMETROS } & \multirow{2}{*}{ RESULTADOS } & \multicolumn{2}{c|}{ Norma INEN 9:2012 } \\
\cline { 2 - 4 } & & Min & Max \\
\hline Densidad a $15^{\circ} \mathrm{C}$ & $1,029 \pm 0,001$ & 1,029 & 1,033 \\
\hline$\%$ Grasa & $3,775 \pm 0,150$ & 3 & - \\
\hline$\%$ S. totales & $18,783 \pm 0,490$ & 11,2 & - \\
\hline \% Acidez exp Ac. Láctico & $0,172 \pm 0,006$ & 0,13 & 0,18 \\
\hline $\mathrm{pH}$ & $6,850 \pm 0,050$ & - & - \\
\hline P. Crioscópico ${ }^{\circ} \mathrm{H}$ & $-0,554 \pm 0,024$ & $-0,555$ & $-0,53$ \\
\hline \% Proteína & $3,384 \pm 0,179$ & 2,9 & - \\
\hline $\begin{array}{l}\text { Ensayo de reductasa (azul de } \\
\text { metileno) }\end{array}$ & Más de 3 horas & 3 & - \\
\hline $\begin{array}{l}\text { Reacción de estabilidad } \\
\text { proteica (prueba } \\
\text { de alcohol) }\end{array}$ & Negativo & $\begin{array}{l}\text { Para leche destinada a } \\
\text { pasteurización: No se } \\
\text { coagulará por la adición de } \\
\text { un volumen igual de alcohol } \\
\text { neutro de 68\% en peso o } \\
75 \% \text { en volumen }\end{array}$ \\
\hline
\end{tabular}

\subsection{Efecto del tratamiento térmico sobre las proteínas de la leche}

En la Figura 1 se representan el valor medio y el análisis con el test de Tukey de las determinaciones de proteína de las cinco repeticiones para cada tratamiento. Se observa que a medida que incrementa la temperatura, la cantidad de proteína desciende respecto a la proteína de la leche cruda. Esto es debido a que al someter la leche a temperatura se produce una pérdida de la solubilidad de las proteínas, y son las proteínas del suero las que coagulan (Lau et al., 1991) y fueron retenidas en la filtración. Estadísticamente no existe una diferencia significativa entre el contenido medio de las proteínas de la leche cruda con la tratada a $65^{\circ} \mathrm{C}$, pero si con el resto de temperaturas. Tampoco se observan diferencias significativas en el porcentaje de proteína entre los tratamientos a 65 y $72{ }^{\circ} \mathrm{C}$, y el de $72{ }^{\circ} \mathrm{C}$ con respecto al del punto de ebullición.

En la Figura 2 se representa el valor medio del porcentaje de desnaturalización de las proteínas, y se puede observar que el tratamiento térmico aumenta la desnaturalización y que estadísticamente son diferentes. 


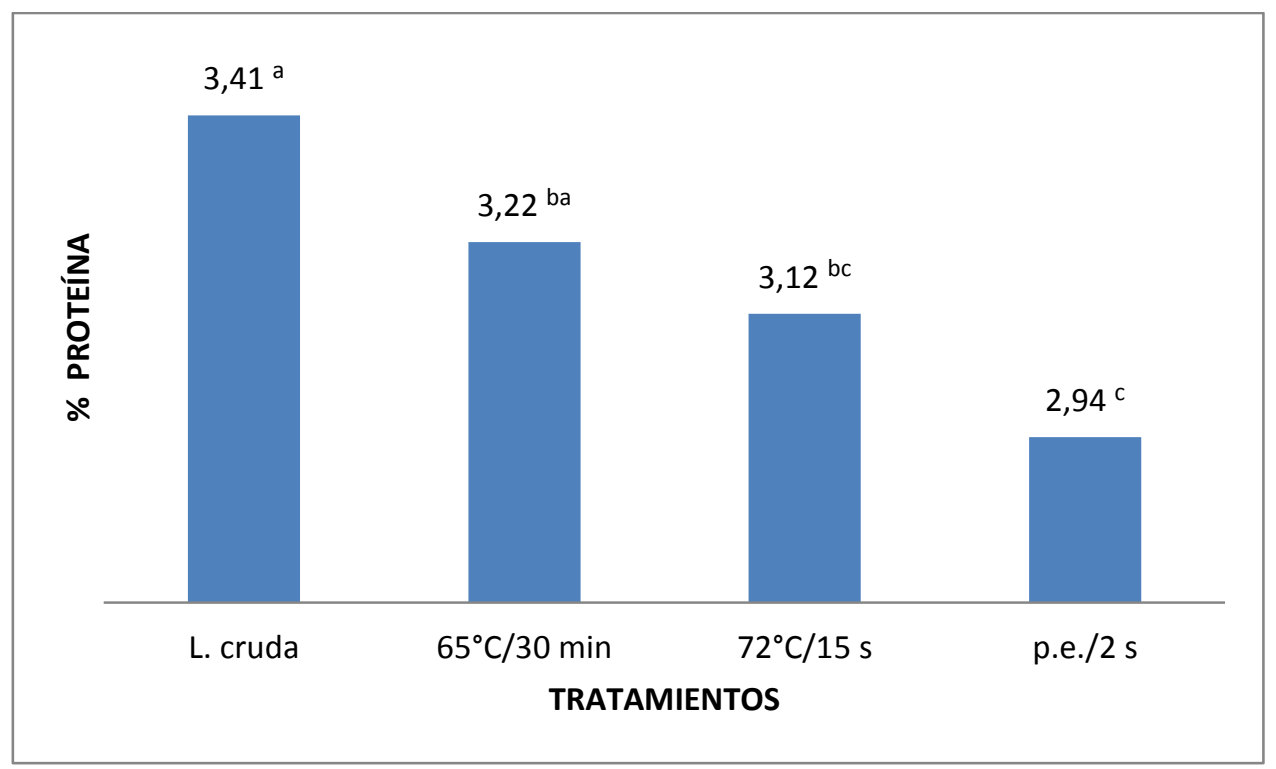

Figura 1. Promedio del Porcentaje de proteína en la leche y análisis de Tukey. Los datos con letras iguales no presentan diferencias significativas.

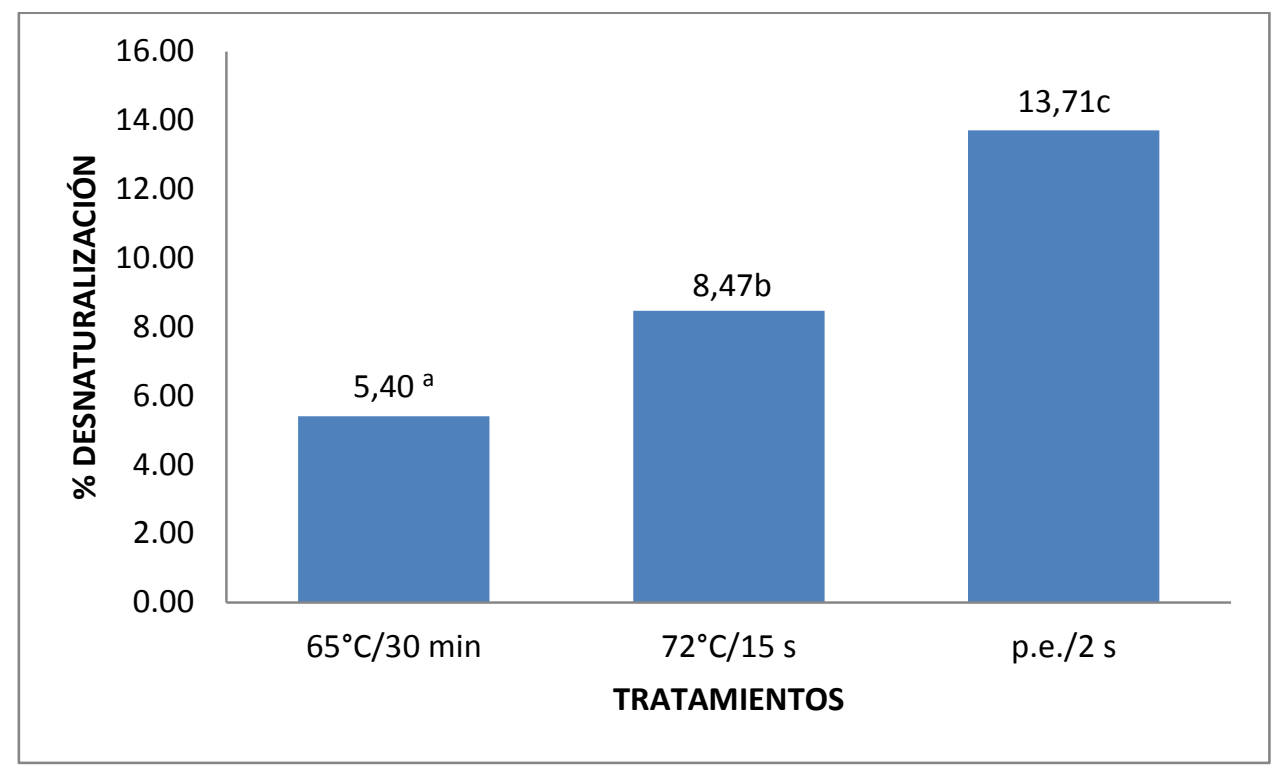

Figura 2. Porcentaje de desnaturalización de la proteína.

Los datos con letras iguales no presentan diferencias significativas

Rynne y sus colaboradores (2004) reportan que en el proceso de pasteurización a $72{ }^{\circ} \mathrm{C} \times 15$ segundos se obtiene un porcentaje de desnaturalización del $7 \%$, valor cercano a $8,47 \pm 0.58 \%$ determinado en este trabajo. A $63^{\circ} \mathrm{C}$ × $30 \mathrm{~min}$ ellos no obtienen desnaturalización de las proteínas; sin embargo, en nuestro estudio a $65^{\circ} \mathrm{C}$ existe un $5.4 \%$, lo cual está de acuerdo con la tendencia en la dependencia de la desnaturalización con la intensidad del tratamiento térmico.

En la Figura 3, se reportan los promedios del porcentaje de humedad determinadas en el queso elaborado en el laboratorio. Se observa un incremento de humedad en los quesos en relación con el tratamiento control, este incremento se debe a la capacidad de retención de agua inducido por el estiramiento (desnaturalización) que sufren las moléculas de las proteínas del suero por acción del calor (Kethireddipalli et al., 2010), la cual provoca además una cuajada débil (Grappin y 
Beuvier, 1997) pero a la vez un incremento en el rendimiento del queso, como se observa en la Figura 4. Estadísticamente los primeros tres tratamientos son significativamente diferentes, pero el tratamiento a $72{ }^{\circ} \mathrm{C}$ y el de punto de ebullición son iguales. Se debe señalar que el porcentaje de humedad de todos los tratamientos cumple con los requisitos de la norma NTE INEN 1528:2012 Primera revisión que para quesos blandos debe tener un valor máximo del $80 \%$.

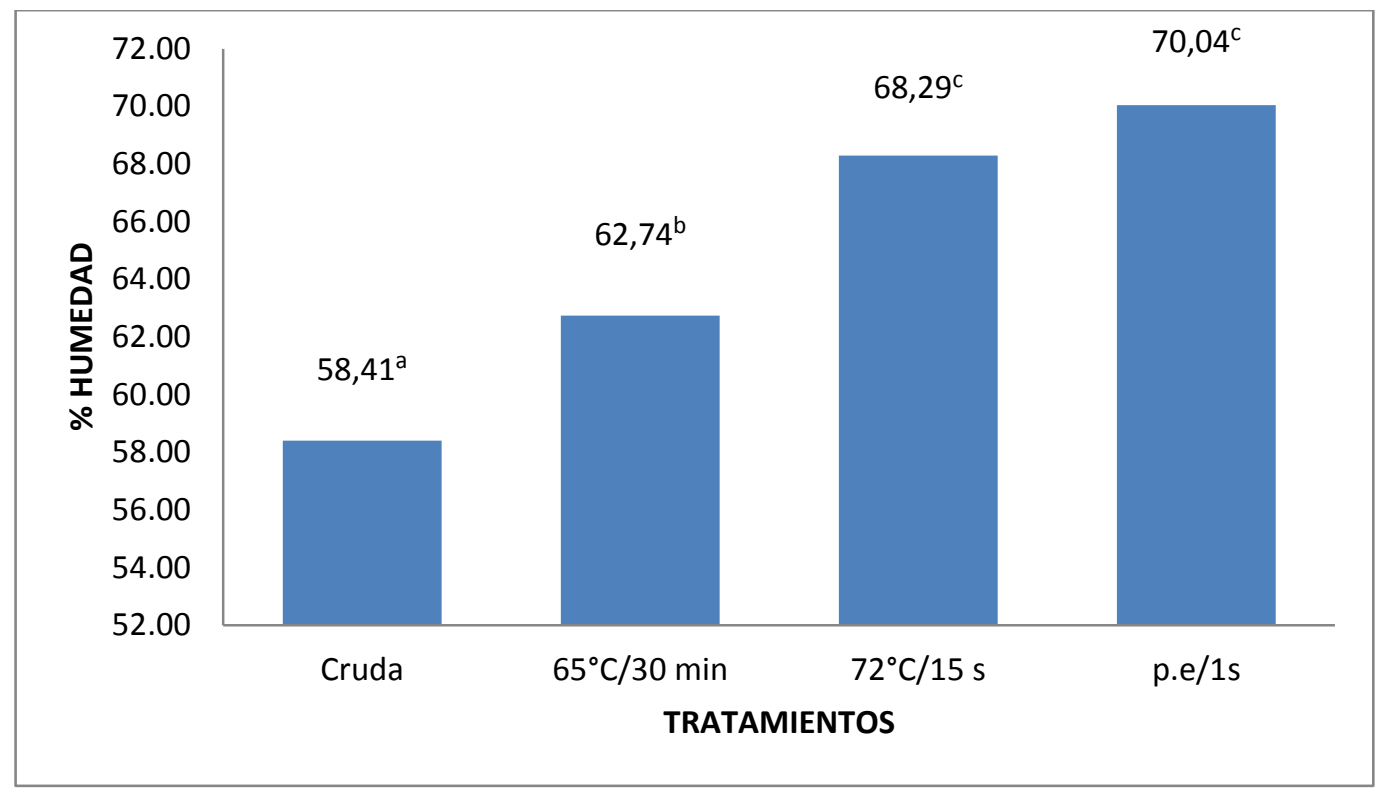

Figura 3. Influencia del tratamiento térmico sobre la humedad. Los datos con letras iguales no presentan diferencias significativas.

La Figura 4, compara los valores promedios de los rendimientos obtenidos a nivel de laboratorio con respecto a los de planta y se puede evidenciar que a nivel de laboratorio el rendimiento aumenta con el aumento de la temperatura. Sin embargo, a nivel de fábrica se produce una disminución en la producción de queso de hasta un $2 \%$ " en los tratamientos a $65^{\circ} \mathrm{C}$ y a $72^{\circ} \mathrm{C}$. Esto ocurre debido a que por efecto de la temperatura se forman coágulos finos (Singh y Waungana, 2001) que en fábrica se van en el lactosuero durante el desuerado y no contribuyen al rendimiento del queso. Se determinó además que no existen diferencias significativas en el rendimiento para los dos primeros tratamientos $\left(65\right.$ y $\left.72{ }^{\circ} \mathrm{C}\right)$. En el caso del tratamiento a punto de ebullición existe un incremento debido a que se adicionó el doble de Cloruro de Calcio para endurecer la cuajada evitando pérdidas durante el desuerado (Sbodio et al., 2010).

Es importante enfatizar que durante el proceso de elaboración del queso en el laboratorio se observó que el aumento de temperatura en la pasteurización de la leche provocó una cuajada débil, es decir con poca firmeza mecánica que dificultó la cortada, y que además la formación del coágulo requirió de más tiempo. Esto es debido al aumento de la hidratación de las proteínas desnaturalizadas cuando se aumenta la temperatura (Schreiber, 2001; Singh y Waungana, 2001).

El calor afectó también al sabor y olor del queso sobre todo en los tratamientos a punto de ebullición, en el que presentó un sabor a cocido y un olor a requesón (queso obtenido del suero). 
Esto se debe a la liberación de los radicales sulfhídrico que se liberan de las $\beta$-lactoglobulina y $\alpha$-lactoalbúmina formando compuestos sulfurados (Hicks, et al., 1986), por lo que este tratamiento no es muy recomendado.

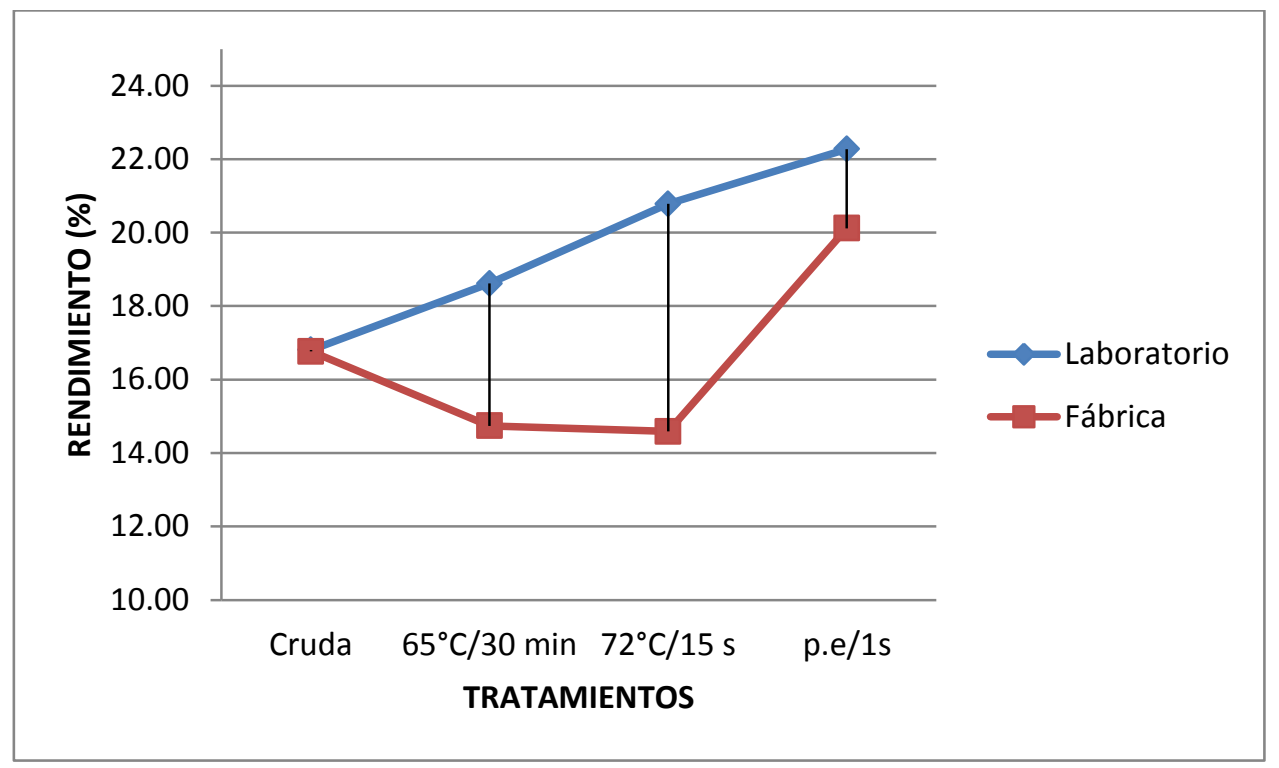

Figura 4. Influencia del tratamiento térmico sobre el rendimiento del queso elaborado en laboratorio y en fábrica.

En la Figura 5, se muestran los valores medios del rendimiento de los procesos de fabricación de queso y mediante el análisis de Tukey a un nivel de significancia menor a 0,05 se puede observar que en planta no hay diferencia significativa entre el rendimiento del queso al producir con leche cruda y pasteurizada a $65^{\circ} \mathrm{C}$ pero si con el resto de temperaturas, tampoco se observan diferencias significativas en el rendimiento entre los tratamientos a 65 y $72{ }^{\circ} \mathrm{C}$, siguiendo esta misma tendencia en el rendimiento de los quesos producidos en el laboratorio.

Se evidencia también que no existen diferencias significativas entre la producción en el laboratorio con la planta cuando se utiliza leche cruda, pero sí para el resto de tratamientos.

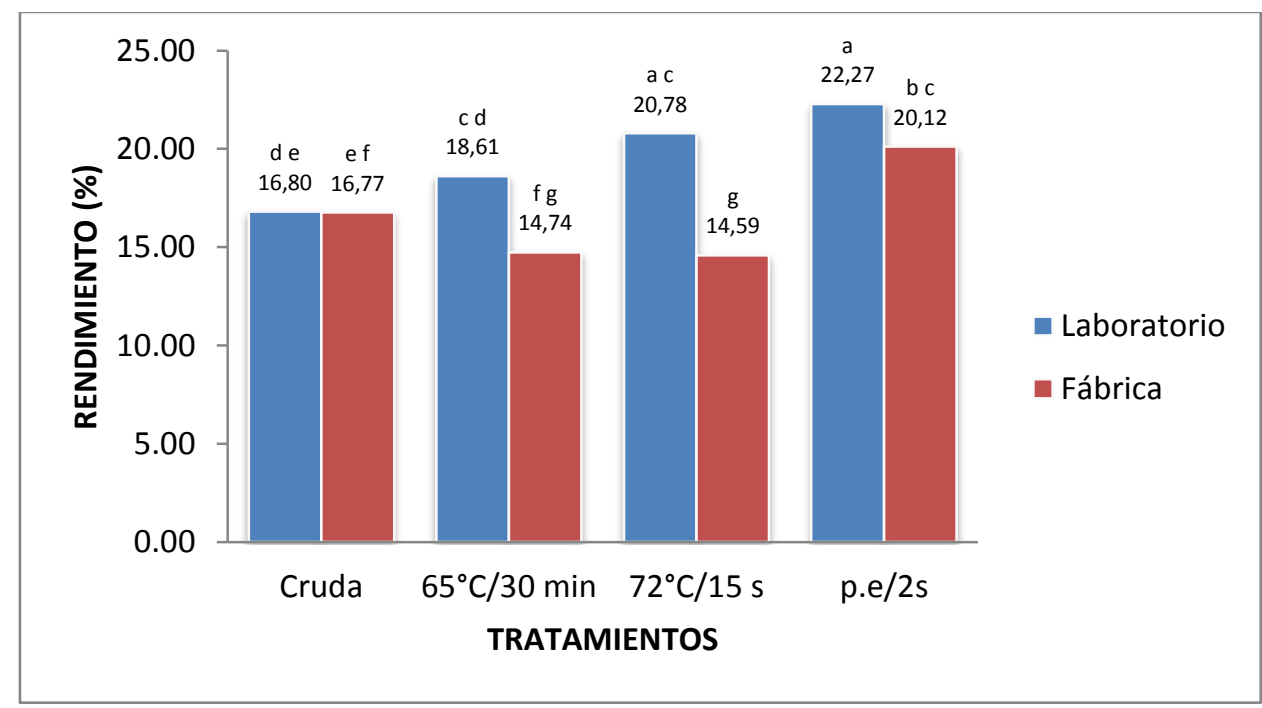

Figura 5. Comparación del rendimiento en la producción del queso fresco elaborado en laboratorio y en fábrica. Los datos con letras iguales no presentan diferencias significativas. 


\section{Conclusiones y Recomendaciones}

En resumen, hemos estudiado los efectos del tratamiento térmico en la pasteurización de la leche y en la fabricación del queso fresco, utilizando leche cruda y tratada a $65^{\circ} \mathrm{C}$ por 30 minutos, $72{ }^{\circ} \mathrm{C}$ por 15 segundos y a ebullición por 2 segundos. Los resultados a nivel de laboratorio reflejan que el incremento de temperatura provoca una mayor desnaturalización de las proteínas, un mayor rendimiento y un aumento de la humedad en el queso en relación al obtenido con la leche cruda. Sin embargo, estadísticamente los resultados demostraron que el tratamiento térmico sí influye en la desnaturalización de las proteínas pero no en el rendimiento del queso. Los resultados obtenidos en la investigación en fábrica revelaron que a temperatura de $65^{\circ}$ y $72{ }^{\circ} \mathrm{C}$ el rendimiento disminuye con relación a la producción con leche cruda, pero estadísticamente no presenta diferencias significativas en el rendimiento para leche pasteurizada a $65{ }^{\circ} \mathrm{C}$ por 30 minutos y la leche cruda.

Entonces podemos concluir que a medida que se incrementa la temperatura en la pasteurización de la leche incrementa el porcentaje de desnaturalización de las proteínas, pero no influyen en el rendimiento de la elaboración del queso, tanto a nivel de laboratorio como de fábrica, cuando la temperatura de pasteurización es de $65^{\circ}$ y $72^{\circ} \mathrm{C}$.

Pese a que la pasteurización de la leche a punto de ebullición da un mayor rendimiento, no se recomienda este procedimiento debido a que se requiere mayor cantidad de cloruro de calcio y el queso tiene un olor a leche cocida.

\section{Agradecimientos}

A la microempresa lácteos "San Salvador" por facilitar la infraestructura y el personal para la ejecución de esta investigación.

\section{Bibliografía}

Grappin, R. y Beuvier, E. (1997). Possible implicationes of milk pasteurization on the manufacture and sensory quality of ripened cheese. International Dairy Jounarl, 7, 751-761

Fennema O. (1985). Food Chemistry. (2th Ed.). New York, U.S.A: Marcel Dekker Inc.

Hicks, L., Onuorah, C., O'Leary, J., y Langlois, E. (1986). Effect of milk quality and low temperature storage on cheese yield a summation. Journal of Dairy Science, 69(3), 649-657.

Kethireddipalli, P., Hill, R., y Dalgleish, G. (2010). Protein interactions in heat-treated milk and effect on rennet coagulation. International Dairy Journal, 20(12), 838-843.

Lau, Y., Barbano, M., y Rasmussen, R. (1991). Influence of pasteurization of milk on protein breakdown in Cheddar cheese during aging. Journal of Dairy Science, 74(3), 727-740. 
Manji, B., y Kakuda, Y. (1987). Determination of whey protein denaturation in heat-processed milks: comparison of three methods. Journal of Dairy Science, 70(7), 1355-1361.

Martinez-Castro, I., Olano, A., y Corzo, N. (1986). Modifications and interactions of lactose with mineral components of milk during heating processes. Food Chem., 21, 211-221.

Rynne, M., Beresford, P., Kelly, L., y Guinee, P. (2004). Effect of milk pasteurization temperature and in situ whey protein denaturation on the composition, texture and heat-induced functionality of half-fat Cheddar cheese. International Dairy Journal, 14(11), 989-1001.

Rodríguez, S. (2002). Ingeniería de la industria alimentaria vol. III Operaciones de conservación de alimentos. Madrid, España: Síntesis S.A.

Sbodio, A.; Tercero, J.; Zannier, S.; Revelli, R. (2010). Tratamiento térmico de leche: influencia del $\mathrm{pH}$ y $\mathrm{CaCl} 2$ en la elaboración de queso Cuartirolo. Revista Internacional del Centro de Información Tecnológica, 21 (5), 107-116

Schreiber, R. (2001). Heat-induced modifications in casein dispersions affecting their rennetability. International Dairy Journal, 11(4), 553-558.

Singh, H., y Waungana, A. (2001). Influence of heat treatment of milk on cheesemaking properties. International Dairy Journal, 11(4), 543-551.

Tornadijo, E., Marra, I., Fontán, G., Prieto, B., y Carballo, J. (1998). La calidad de la leche destinada a la fabricación de queso. Cyta Journal of Food, 2(2), 79-91. 